\title{
Laparoscopic Heller-Dor Is an Effective Treatment for Esophageal-Gastric Junction Outflow Obstruction
}

\author{
Renato Salvador ${ }^{1}$ (D) $\cdot$ Luca Provenzano $^{1} \cdot$ Giulia Nezi $^{1} \cdot$ Giovanni Capovilla $^{1} \cdot$ Loredana Nicoletti $^{1}$. \\ Elisa Sefora Pierobon ${ }^{1} \cdot$ Lucia Moletta $^{1} \cdot$ Michele Valmasoni $^{1} \cdot$ Stefano Merigliano ${ }^{1} \cdot$ Mario Costantini $^{1}$
}

Received: 1 March 2021 / Accepted: 18 April 2021 / Published online: 6 May 2021

(C) 2021 The Author(s)

\begin{abstract}
Background The treatment of esophagogastric junction outflow obstruction (EGJOO) currently mirrors that of achalasia, but this is based on only a few studies on small case series. The aim of this prospective, controlled study was to assess the outcome of laparoscopic Heller-Dor (LHD) in patients with EGJOO, as compared with patients with esophageal achalasia.

Materials and Methods Between 2016 and 2019, patients with manometric diagnosis of idiopathic EGJOO and patients with radiological stage I achalasia, both treated with LHD, were compared. The achalasia group was further analyzed by subgrouping the patients based on the manometric pattern. Treatment failure was defined as the persistence or reoccurrence of an Eckardt score $>3$ or the need for retreatment.

Results During the study period, 150 patients were enrolled: 25 patients had EGJOO and 125 had radiological stage I achalasia (25 pattern I, 74 pattern II, and 26 pattern III). The median follow-up was 24 months (IQR: 34-16). Treatment was successful in $96 \%$ of patients in the EGJOO group and in $96 \%$ of achalasia patients with pattern I, $98.7 \%$ in those with pattern II, and $96.2 \%$ of those with pattern III $(p=0.50)$. High-resolution manometry showed a reduction in the LES resting pressure and integrated relaxation pressure for all patients in all 4 groups $(p<0.001)$.

Conclusion This is the first comparative study based on prospective data collection to assess the outcome of LHD in patients with EGJOO. LHD emerged as an effective treatment for EGJOO, with an excellent success rate, comparable with the procedure's efficacy in treating early-stage achalasia.
\end{abstract}

Keywords Heller-Dor · EGJOO $\cdot$ High-resolution manometry

\section{Background}

Esophago-gastric junction outflow obstruction (EGJOO) is a relatively new clinical entity revealed by high-resolution manometry (HRM). According to the Chicago Classification, the disorder is due to a poorly relaxing lower esophageal sphincter (LES), with integrated relaxation pressure (IRP) $>15 \mathrm{mmHg}$, and a preserved esophageal peristalsis. ${ }^{1}$

This manometric diagnosis can have two different etiologies, i.e., idiopathic or secondary EGJOO. The latter may be

Renato Salvador

renato.salvador@unipd.it

1 Department of Surgical, Oncological and Gastroenterological Sciences, University of Padova, School of Medicine, Clinica Chirurgica 3, Azienda Ospedale Università di Padova, Padova, Italy caused by any mechanical obstruction of the esophagus, such as esophageal strictures, eosinophilic esophagitis, giant hiatal hernia, prior fundoplication or bariatric surgery, or malignancy. ${ }^{2}$ Patients with no such anatomical obstructions are diagnosed with idiopathic EGJOO. The main clinical manifestations of idiopathic EGJOO are dysphagia, chest pain, and regurgitation. ${ }^{3}$ For the time being, there are no published guidelines on the management and treatment of this recently identified motility disorder. Many authors have suggested using the same treatment for EGJOO as for achalasia, but this recommendation is based on only a few studies with small case series. Oral calcium-channel blockers are the initial treatment of choice, but achieve low rates of symptom relief of around $35 \%$. $^{4}$

The aim of this prospective, controlled study was to examine the outcome of laparoscopic Heller-Dor (LHD) in patients with idiopathic EGJOO, as compared with that of patients with radiological grade I esophageal achalasia. 


\section{Materials and Methods}

\section{EGJOO Padova Protocol}

All patients with a diagnosis of idiopathic EGJOO (i.e., not postoperative or associated to hiatal hernia or esophageal stenosis) who underwent HRM (Manoview, Medtronic Minnesota, USA) at the Department of Surgical, Oncological, and Gastroenterological Sciences, University of Padova (Italy) from 2016 to 2019, and referred for dysphagia or food regurgitation, were prospectively collected. Patients with a manometric diagnosis of idiopathic EGJOO after being referred for chest pain, heartburn, or other extra-esophageal symptoms were ruled out. EGJOO was diagnosed on the grounds of accepted esophageal motility characteristics, i.e., IRP $>15 \mathrm{mmHg}$ with a preserved esophageal peristalsis, according to the Chicago Classification v3.0 criteria. $^{1}$

Naïve EGJOO patients (i.e., patients who did not have a previous endoscopic treatment) were first given medical treatment with $\mathrm{Ca} 2+$ channel blockers for 6 months. Then patients were "restaged" on the strength of repeat HRM and the symptom score (SS). Patients whose SS had not improved and/or whose IRP had not decreased were scheduled for LHD (Fig. 1). Patients referred to our center with a previous diagnosis of EGJOO who had already been treated with botox injections, pneumatic dilations, or $\mathrm{Ca} 2+$ channel blockers were scheduled upfront for LHD.

Patients with EGJOO who underwent LHD were compared with patients with radiological stage I achalasia (i.e., undergoing the same procedure during the same period. The achalasia group was subgrouped for the purposes of our analyses based on patients' manometric patterns I, II, or III.

Patients' demographics, clinical data, and symptoms were prospectively collected with a dedicated database adopted at our center. Patients' demographics, clinical data, and symptoms were collected with a dedicated questionnaire adopted at our center. To evaluate the symptoms score (SS), we used the Eckardt score. $^{5}$

Before LHD, all patients had a barium swallow X-ray to assess the diameter of the esophagus, ${ }^{6}$ and endoscopy to rule out cardia malignancies, eosinophilic esophagitis, and/or other esophageal diseases.

The surgical technique for LHD has been described in detail elsewhere ${ }^{7}$ and was performed in the same way by two expert surgeons (RS, MC). Briefly, a myotomy 7-8 cm long was performed after dissecting only the anterior wall of the esophagus, extending the myotomy $1.5-2 \mathrm{~cm}$ on the gastric side. During the procedure, a 30-mm Rigiflex balloon was placed inside the esophageal lumen at the cardia level, using an endoscopically positioned guidewire. The balloon was then gently inflated with air and deflated while the muscle fibers were being cut. A partial anterior fundoplication according to the technique described by Dor was performed and sutured to the edges of the myotomy with three stitches on each side. The more proximal suture included the homolateral pillar of the hiatus to keep the fundoplication high around the esophagus.

The postoperative follow-up included examining patients 1 , 6 , and 12 months after surgery, and every 2 years thereafter,

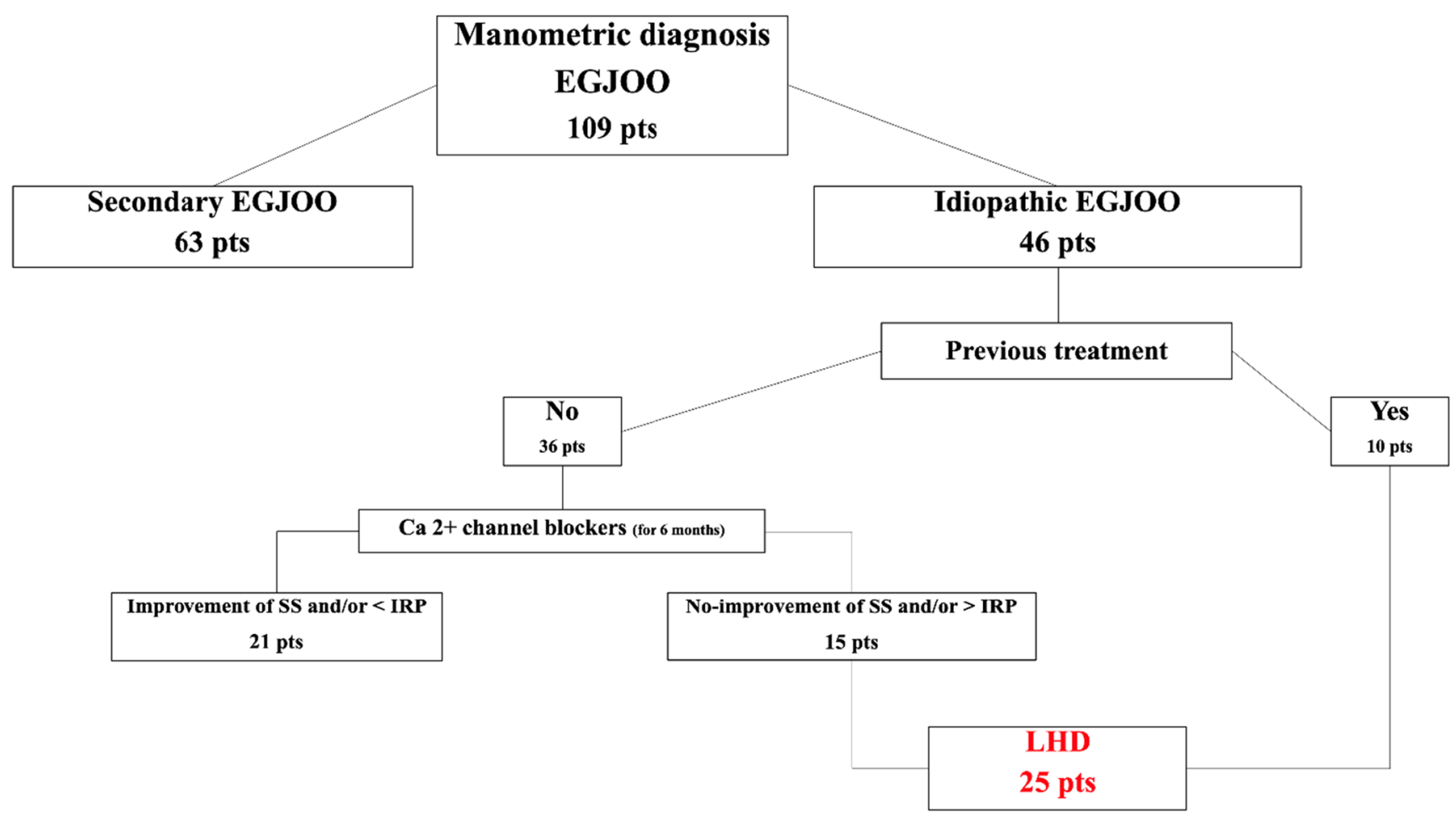

Fig. 1 Flow-chart for selection of patients with a manometric diagnosis of EGJOO complaining of dysphagia and/or food-regurgitation 
using the same questionnaire that was administered preoperatively. Barium swallow X-ray was required 1 month after LHD and in the event of recurrent symptoms. HRM was performed 6 months after LHD (Fig. 2), together with 24-h pH monitoring to check for any abnormal acid exposure of the distal esophagus. Endoscopy was recommended 12 months after LHD, and then every 2 years thereafter, ${ }^{8}$ to identify and control any complications of gastroesophageal reflux and rule out any (albeit rare) neoplastic degeneration (Table 1).

Treatment failure was defined as the persistence or reoccurrence of an Eckardt score $>3$ or the need for retreatment. ${ }^{9}, 10$

The study was approved by the institutional review board at Padova General Hospital and by the Research Committee of the Department of Surgical, Oncological, and Gastroenterological Sciences at Padova University. Research is being reported in line with the STROCCS criteria. ${ }^{11}$ This study was registered in the Research Registry (research registry 6562).

\section{Statistical analysis}

Continuous data were expressed as medians and interquartile ranges (IQR), and categorical data as numbers and percentages. Continuous and categorical data were compared between the four study groups using the Kruskal-Wallis test and Fisher's test, respectively. All tests were two-sided and a $p$ value of less than 0.05 was considered statistically significant.

\section{Results}

During the study period, we examined 109 patients referred for dysphagia and/or food-regurgitation who had EGJOO diagnosed on HRM. Secondary EGJOO (i.e., associated with prior fundoplication, hiatal hernia, esophageal stenosis, or other causes) was identified in 63 patients, who were therefore excluded from the study.
Idiopathic EGJOO was diagnosed in 46 patients. Of the 36 previously untreated, 15 patients experienced no symptom improvement or reduction in IRP after 6 months of therapy with $\mathrm{Ca} 2+$ blockers. These patients were offered LHD and entered the study together with the 10 patients who had previously been treated endoscopically. The study population thus included 25 patients (M:F=15:10). Figure 1 shows the flowchart for the selection of our study population.

Our control population included 125 patients with radiological stage I achalasia. According to the Chicago Classification v3.0, 25 patients were classified as having pattern I, 74 had pattern II, and 26 had pattern III.

Table 2 shows the demographic and clinical parameters of the study population and control group. A history of endoscopic treatments (pneumatic dilations, botox injections, or both) was more common in the EGJOO group (40\%) than in any of the 3 achalasia subgroups (16\% of patients with pattern I, $12.2 \%$ of those with pattern II, and $7.7 \%$ of those with pattern III) $(p=0.01)$.

The EGJOO group had a lower preoperative IRP (20 mmHg, IQR: 19-23) than patients with achalasia (pattern I: $27 \mathrm{mmHg}$, IQR: 22-29; pattern II: $35 \mathrm{mmHg}$, IQR: 26-46; pattern III: $26 \mathrm{mmHg}$, IQR: $20-39)(p<0.001)$.

The surgical procedure was completed laparoscopically in all patients. Mortality was nil. Intraoperative perforations were detected in two patients, one with EGJOO and one with pattern II achalasia. Both of these mucosal tears were repaired during the LHD procedure and were without further consequences. Gastrografin swallow X-ray performed on the first postoperative day after LHD revealed no mucosal tears in any of the patients.

The median follow-up was 24 months (IQR: 34-16). All patients had a lower SS after LHD; the median of preoperative SS was 7 (IQR: 5-8) while the postoperative was 0 (IQR: 0-1) $(p<0.001)$. During the follow-up, the outcome was considered satisfactory in $96 \%$ of patients in the EGJOO group, and in $96 \%$ in the achalasia pattern I subgroup, $98.7 \%$ in the achalasia pattern II subgroup, and $96.2 \%$ in the achalasia pattern III a

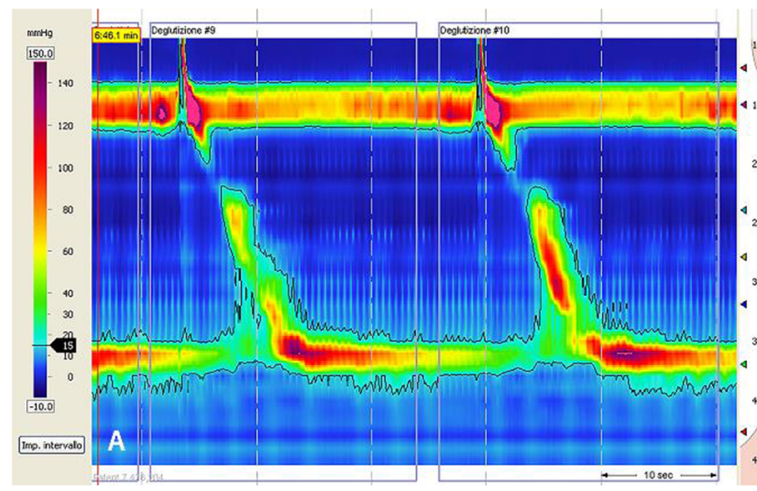

b

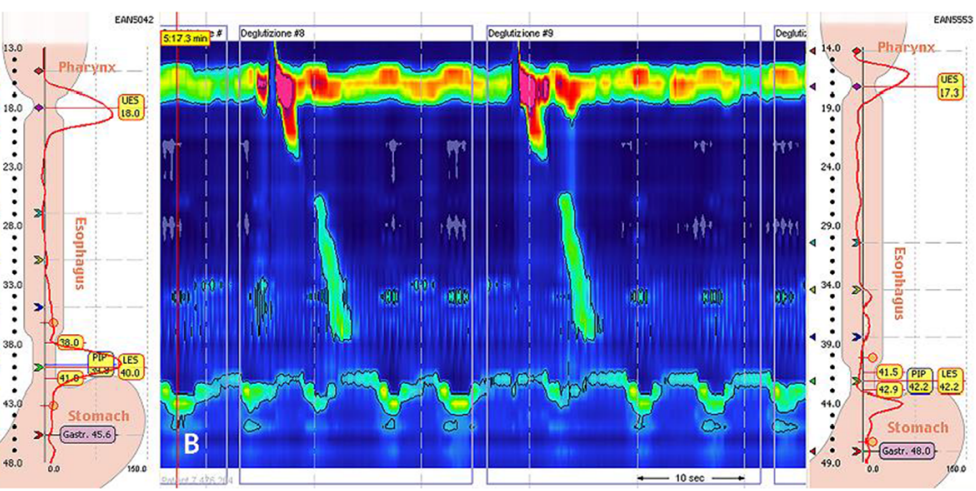

Fig. 2 High-resolution manometry pictures of EGJOO: a preoperatively and b postoperatively 
Table 1 Follow-up procedures and timing

\begin{tabular}{|c|c|c|c|c|}
\hline Procedure & 1 month & 6 months & 12 months & Every 2 years \\
\hline Symptom questionnaire (Eckardt score) & घ & घ & - & - \\
\hline Barium swallow & घ & & & \\
\hline High-resolution manometry & & घ & & \\
\hline 24-h pH monitoring & & ! & & \\
\hline Endoscopy & & & - & - \\
\hline
\end{tabular}

subgroup $(p=0.50)$. There were four treatment failures in all, one in each group or subgroup. All patients whose surgery failed subsequently underwent one or more endoscopic pneumatic dilation treatments, obtaining an improvement in their symptom scores.

Postoperative HRM showed a reduction in the LES resting pressure and IRP in all patients in all 4 groups/subgroups $(p<0.001)$. The median postoperative IRP was similar in all groups as well: $9 \mathrm{mmHg}$ (IQR: $8-12$ ) in the EGJOO group, $11 \mathrm{mmHg}$ (IQR: 10-12) in the pattern I subgroup, $9 \mathrm{mmHg}$ (IQR: 6-12) in the pattern II subgroup, and $12 \mathrm{mmHg}$ (IQR: $7-14)$ in the pattern III subgroup ( $p=0.51)$. In addition, 24-h $\mathrm{pH}$ monitoring showed comparable proportions of postoperative abnormal acid exposure in all groups/subgroups, affecting $14.3 \%$ of EGJOO patients, $8.3 \%$ of achalasia pattern I patients, $8.9 \%$ of achalasia pattern II patients, and $10 \%$ of achalasia pattern III patients $(p=0.49)$ (Table 3$)$.

\section{Discussion}

The advent and now widespread diffusion of HRM prompted a new classification of esophageal motility disorders, the Chicago Classification, which is currently in its $3^{\text {rd }}$ version. ${ }^{1}$ This classification is based on a dichotomous hierarchical tree where the main distinction is between a normal and an abnormal LES relaxation (IRP $<15 \mathrm{mmHg}$ or $>15 \mathrm{mmHg}$, respectively). Combined with the absence of any peristalsis, an abnormal LES relaxation is the main characteristic of achalasia, in its 3 different manometric patterns. A poor LES relaxation associated with a preserved peristalsis (and therefore lacking one of the defining features of achalasia) can still interfere with bolus transit to the stomach and cause dysphagia. This major motility disorder is characterized by an elevated LES relaxation pressure (IRP $>15 \mathrm{mmHg}$ ) associated with an intact peristalsis.

EGJOO is a relatively new manometric diagnostic entity, and its etiology may be idiopathic or secondary to mechanical obstructions, such as esophageal strictures, eosinophilic esophagitis, giant hiatal hernia, prior fundoplication or bariatric surgery, or malignancy. ${ }^{2}$ Patients without any such anatomical obstruction are diagnosed with idiopathic EGJOO. The pathophysiology of "idiopathic" EGJOO is unclear, but most authors see it as a precursor or variant of achalasia, as clearly suggested by its description in the Chicago Classification as "incompletely expressed achalasia." This theory is only supported, however, by small case series in which some EGJOO patients developed achalasia after treatment. $^{12}$

EGJOO is a relatively uncommon condition ${ }^{13}$; as in achalasia, the main clinical manifestations of idiopathic EGJOO are dysphagia, chest pain and regurgitation, ${ }^{3}$ and treatments that aim to relieve the idiopathic obstruction (i.e., to improve esophago-gastric junction relaxation) are the most effective. So far, the management of this novel motility disorder has been based on a handful of studies on small case series, in the light of experience gained with achalasia.

Table 2 Pre-operative demographic and clinical findings in the four groups of patients

\begin{tabular}{|c|c|c|c|c|c|}
\hline & EGJOO & Achalasia pattern I & Achalasia pattern II & Achalasia pattern III & $p$ value \\
\hline Patients $(n)$ & 25 & 25 & 74 & 26 & \\
\hline Age (years)* & $65(50-74)$ & $44(30-60)$ & $48(33-61)$ & $56(39-66)$ & $<0.01$ \\
\hline $\operatorname{Sex}(M: F)$ & $15: 10$ & $12: 13$ & $30: 44$ & $19: 7$ & 0.007 \\
\hline Symptom duration (months)* & $34(21-60)$ & $24(12-84)$ & $24(23-36)$ & $30(23-60)$ & 0.44 \\
\hline Symptom score (Eckardt score)* & $5(3-6)$ & $8(6-9)$ & $7(6-8)$ & $7(4-9)$ & $<0.01$ \\
\hline Previous endoscopic treatment ${ }^{\wedge}$ & $10(40 \%)$ & $4(16 \%)$ & $9(12.2 \%)$ & $2(7.7 \%)$ & 0.01 \\
\hline Esophageal diameter $(\mathrm{mm})^{*}$ & $21(20-29)$ & $30(24-30)$ & $27(23-30)$ & $25(20-26)$ & 0.11 \\
\hline LES resting pressure $(\mathrm{mmHg}) *$ & $42(27-50)$ & $43(30-53)$ & $50(41-60)$ & $49(35-65)$ & 0.051 \\
\hline $\operatorname{IRP}(\mathrm{mmHg})^{*}$ & $20(19-23)$ & $27(22-29)$ & $35(26-46)$ & $26(20-39)$ & $<0.001$ \\
\hline
\end{tabular}

Data are shown as * median (IQR), ^ number of patients $(\%)$

Abbreviations: $E G J O O$ esophagogastric junction outflow obstruction, LES lower esophageal sphincter, IRP integrated relaxation pressure 
Table 3 Post-operative parameters

\begin{tabular}{|c|c|c|c|c|c|}
\hline & EGJOO & Achalasia pattern I & Achalasia pattern II & Achalasia pattern III & $p$ value \\
\hline Symptom score (Eckardt score)* & $0(0-1)$ & $0(0-1)$ & $0(0-1)$ & $0(0-0)$ & 0.20 \\
\hline LES resting pressure $(\mathrm{mmHg})^{*}$ & $19(15-22)$ & $17(16-18)$ & $18(13-23)$ & $17(16-18)$ & 0.41 \\
\hline $\operatorname{IRP}(\mathrm{mmHg})^{*}$ & $9(8-12)$ & $11(10-12)$ & $9(6-12)$ & $12(7-14)$ & 0.51 \\
\hline Positive outcome & $96 \%$ & $96 \%$ & $98.7 \%$ & $96.2 \%$ & 0.50 \\
\hline Abnormal 24-h pH-monitoring & $14.3 \%$ & $8.3 \%$ & $8.9 \%$ & $10 \%$ & 0.49 \\
\hline
\end{tabular}

Data are shown as * median $(\mathrm{IQR}),{ }^{\wedge}$ number of patients $(\%)$

Abbreviations: EGJOO esophagogastric junction outflow obstruction, LES lower esophageal sphincter, IRP integrated relaxation pressure

Symptoms in patients with EGJOO do not always require treatment and their final outcome varies, so deciding which patients need intervention is a key challenge in these patients' management. ${ }^{3,13}$ Our study confirmed this point of view because we observed that patients who responded to medical management did not present any radiological or manometric difference compared to patients who had not a clinical improvement with $\mathrm{Ca} 2+$ channel blockers. Some authors suggest that $44-52 \%$ of patients diagnosed with EGJOO improve without any pharmacological or surgical therapy. ${ }^{3,14,15}$ The present study enrolled only idiopathic EGJOO patients with symptoms of dysphagia and food regurgitation who did not respond to medical treatment.

Treatment options for idiopathic EGJOO described in the literature include medical, endoscopic and surgical approaches. Medical treatments such as $\mathrm{Ca} 2+$ channel blockers and long-acting nitrates have been used, but the few data reported by Perez-Fernandez et al. and other authors point to low clinical response rates, involving only about $50 \%$ of patients with EGJOO.$^{14}$ Porter et al. reported on the treatment of 36 EGJOO patients with botox injections. Their survival analysis showed that persistent symptom relief from a single botox injection at 2 years was just $16.8 \% .{ }^{16}$ Some authors also found that some patients treated with botox injections progressed to type 3 achalasia within 20 months of this treatment. ${ }^{2}$

Given that idiopathic EGJOO appears to be achalasia's precursor, Clayton et al. treated patients with pneumatic dilations. They found this a safe and effective initial treatment for idiopathic EGJOO in patients with dysphagia and abnormal esophageal emptying. The outcome was positive in $67 \%$ of patients $(22 / 33)$ treated with a single dilation using a $30-\mathrm{mm}$ balloon, and in $79 \%$ of patients retreated with a $35-\mathrm{mm}$ balloon, after a median follow-up of around 2 years. ${ }^{4}$

In an international multicenter study, Khashab et al. assessed the clinical outcomes of peroral endoscopic myotomy (POEM) in patients with disorders other than achalasia, i.e., EGJOO, diffuse esophageal spasm, and jackhammer esophagus. They reported a positive outcome in $93 \%$ of EGJOO patients after POEM. The main limitation of this study is the short follow-up, which was only about 6 months. ${ }^{17}$ These positive findings were replicated by Okeke et al., however, who treated three patients with POEM, obtaining a $100 \%$ success rate after long-term follow-up. ${ }^{18}$

The aim of the present study was to ascertain whether LHD has a role in the treatment of patients with idiopathic EGJOO, a hypothesis that - in our opinion - is confirmed by our data. For now, there are no published studies dedicated to examining the role of LHD for this recently identified clinical entity. In a recent review, Clayton et al. sought to collect all the cohorts of EGJOO patients treated with Heller myotomy: they found only two case series concerning a total of four patients treated, and all four of them experienced lasting symptom relief. $^{3,} 4,19$ Lin et al. published a case report on a robotassisted extended esophageal myotomy and Belsey-Mark IV fundoplication performed in a patient diagnosed with EGJOO who had suffered from severe headache using calcium channel blockers and nitrites for pain control. At one-year followup, the patient's chest pain and dysphagia had improved. ${ }^{20}$

Our study confirmed the value of surgical myotomy for EGJOO, showing that patients who underwent LHD achieved symptom relief in $96 \%$ of cases. This figure is comparable with the results achieved at our center using the same procedure in patients with esophageal achalasia. ${ }^{21-23}$ Judging from our results, moreover, LHD in EGJOO was also comparable with LHD for esophageal achalasia in terms of its influence on any onset of postoperative gastroesophageal reflux.

This is the first comparative study based on prospective data collection to assess the outcome of LHD in patients with EGJOO. It has some intrinsic limitations, however, that need to be mentioned. The main limitation concerns the number of patients considered was small (though ours is the secondlargest cohort of patients treated for EGJOO). A second limitation may be the exclusion of EGJOO who were referred for chest pain only (without dysphagia or food regurgitation).

\section{Conclusion}

We are nonetheless convinced that LHD could be an effective treatment for EGJOO, comparable with what the same procedure can achieve in early-stage achalasia. Further studies with longer follow-up and a larger cohort of EGJOO patients need to 
confirm our results. LHD should be offered to EGJOO patients in dedicated center only, with great experience with this operation and esophageal diseases. Additional studies might better pinpoint EGJOO patients and help us to establish whether this condition is a variant or an early stage of achalasia.

Acknowledgements The authors acknowledge AMAE - ONLUS (Association of Patients with Achalasia).

Author Contribution Study design: Salvador, Costantini, Provenzano, Valmasoni, and Nezi

Data acquisition: Salvador, Provenzano, Capovilla, Nezi, Nicoletti, and Costantini

Data interpretation: Salvador, Costantini, Provenzano, Valmasoni, Capovilla, and Merigliano

Drafting of the manuscript: Salvador, Costantini, Provenzano, Nezi, Moletta, Pierobon, Valmasoni, Capovilla, Nicoletti, and Merigliano

Final approval: Salvador, Costantini, Provenzano, Nezi, Moletta, Pierobon, Valmasoni, Capovilla, Nicoletti, and Merigliano

Agreement to be accountable for all aspects of the work: Salvador, Costantini, Provenzano, Nezi, Moletta, Pierobon, Valmasoni, Capovilla, Nicoletti, and Merigliano

Funding Open access funding provided by Università degli Studi di Padova within the CRUI-CARE Agreement.

\section{Declarations}

Conflict of Interest The authors declare no competing interests.

Open Access This article is licensed under a Creative Commons Attribution 4.0 International License, which permits use, sharing, adaptation, distribution and reproduction in any medium or format, as long as you give appropriate credit to the original author(s) and the source, provide a link to the Creative Commons licence, and indicate if changes were made. The images or other third party material in this article are included in the article's Creative Commons licence, unless indicated otherwise in a credit line to the material. If material is not included in the article's Creative Commons licence and your intended use is not permitted by statutory regulation or exceeds the permitted use, you will need to obtain permission directly from the copyright holder. To view a copy of this licence, visit http://creativecommons.org/licenses/by/4.0/.

\section{References}

1. Kahrilas PJ, Bredenoord AJ, Fox M, Gyawali CP, Roman S, Smout AJ, Pandolfino JE; International High-Resolution Manometry Working Group. The Chicago Classification of Esophageal Motility Disorders, v3.0 Neurogastroenterol Motil. 2015;27(2):160-74.

2. Clayton SB, Patel R, Richter JE. Functional and anatomic esophagogastic junction outflow obstruction: manometry, timed barium esophagram findings, and treatment outcomes. Clin Gastroenterol Hepatol. 2016;14(6):907-911.

3. Lynch KL, Yang YX, Metz DC, Falk GW. Clinical presentation and disease course of patients with esophagogastric junction outflow obstruction. Dis Esophagus. 2017;30(6):1-6. doi: https://doi. org/10.1093/dote/dox004.

4. Clayton SB, Shin CM, Ewing A, Blonski W, Richter J. Pneumatic dilation improves esophageal emptying and symptoms in patients with idiopathic esophago-gastric junction outflow obstruction. Neurogastroenterol Motil. 2019;31(3):e13522. doi: https://doi.org/ 10.1111/nmo.13522. Epub 2018 Dec 10

5. Eckardt VF, Aignherr C, Bernhard G. Predictors of outcome in patients with achalasia treated by pneumatic dilation. Gastroenterology 1992;103:1732-38.

6. Patti MG, Fei CV, Diener U, Tamburini A, Arcerito M, Safadi B, Way LW. Laparoscopic Heller myotomy relieves dysphagia in achalasia when the esophagus is dilated. Surg Endosc. 1999;13(9):843-847. doi:https://doi.org/10.1007/s004649901117

7. Ancona E, Peracchia A, Zaninotto G, et al. Heller laparoscopic cardiomyotomy with antireflux anterior fundoplication (Dor) in the treatment of esophageal achalasia. Surg Endosc. 1993;7(5): 459-61.

8. Salvador R, Costantini M, Zaninotto G, et al. The preoperative manometric pattern predicts the outcome of surgical treatment for esophageal achalasia. J Gastrointest Surg. 2010;14(11):1635-45.

9. Boeckxstaens GE, Annese V, des Varannes SB, Chaussade S, Costantini M, Cuttitta A, Elizalde JI, Fumagalli U, Gaudric M, Rohof WO, Smout AJ, Tack J, Zwinderman AH, Zaninotto G, Busch OR; European Achalasia Trial Investigators. Pneumatic dilation versus laparoscopic Heller's myotomy for idiopathic achalasia. N Engl J Med. 2011;364(19):1807-16. doi: https://doi.org/10. 1056/NEJMoa1010502.

10. Costantini A, Familiari P, Costantini M, Salvador R, Valmasoni M, Capovilla G, Landi R, Mangiola F, Provenzano L, Briscolini D, Merigliano S, Costamagna G. Poem Versus Laparoscopic Heller Myotomy in the Treatment of Esophageal Achalasia: A CaseControl Study from Two High Volume Centers Using the Propensity Score. J Gastrointest Surg. 2020;24(3):505-515. doi: https://doi.org/10.1007/s11605-019-04465-w. Epub 2019 Dec 17.

11. Agha R, Abdall-Razak A, Crossley E, Dowlut N, Iosifidis C and Mathew G, for the STROCSS Group. The STROCSS 2019 Guideline: Strengthening the Reporting of Cohort Studies in Surgery. International Journal of Surgery 2019;72:156-165

12. Richter JE, Clayton SB. Diagnosis and management of esophagogastric junction outflow obstruction. Am J Gastroenterol 2019;114:544-547

13. Triadafilopoulos G, Clarke JO. Clinical and manometric characteristics of patients with oesophagogastric outflow obstruction: towards a new classification. BMJ Open Gastroenterol. 2018;5(1): e000210. doi: https://doi.org/10.1136/bmjgast-2018-000210. eCollection 2018.

14. Perez-Fernandez MT, Santander C, Marinero A, BurgosSantamaria D, Chavarria-Herbozo C. Characterization and follow-up of esophagogastric junction outflow obstruction detected by high-resolution manometry. Neurogastroenterol Motil. 2016;28(1):116-126.

15. van Hoeij FB, Smout AJ, Bredenoord AJ. Characterization of idiopathic esophagogastric junction outflow obstruction. Neurogastroenterol Motil 2015; 27: 1310-6.

16. Porter RF, Gyawali CP. Botulinum toxin injection in dysphagia syndromes with preserved esophageal peristalsis and incomplete lower esophageal sphincter relaxation. Neurogastroenterol Motil. 2011;23(2):139-44, e27-8. doi: https://doi.org/10.1111/j.13652982.2010.01604.x. Epub 2010 Oct 1

17. Khashab MA, Familiari P, Draganov PV, Aridi HD, Cho JY, Ujiki M, Rio Tinto R, Louis H, Desai PN, Velanovich V, Albéniz E, Haji A, Marks J, Costamagna G, Devière J, Perbtani Y, Hedberg M, Estremera F, Martin Del Campo LA, Yang D, Bukhari M, Brewer O, Sanaei O, Fayad L, Agarwal A, Kumbhari V, Chen YI. Peroral endoscopic myotomy is effective and safe in non-achalasia esophageal motility disorders: an international multicenter study. Endosc Int Open. 2018;6(8):E1031-E1036. doi: https://doi.org/10.1055/a0625-6288. Epub 2018 Aug 10. 
18. Okeke FC, Raja S, Lynch KL, et al. What is the clinical significance of esophagogastric junction outflow obstruction? Evaluation of 60 patients at a tertiary referral center. Neurogastroenterol Motil. 2017;29:e13061

19. Scherer JR, Kwiatek MA, Soper NJ, Pandolfino JE, Kahrilas PJ. Functional esophagogastric junction obstruction with intact peristalsis: a heterogeneous syndrome sometimes akin to achalasia. $\mathrm{J}$ Gastrointest Surg. 2009;13(12):2219-25. doi: https://doi.org/10. 1007/s11605-009-0975-7. Epub 2009 Aug 12.

20. Lin KH, Lee SC, Huang TW, Huang HK. Esophagogastric junction outflow obstruction-related functional chest pain treated using robotic-assisted thoracoscopic esophageal myotomy. J Thorac Dis 2017;9(5):E432-E436. doi: https://doi.org/10.21037/jtd.2017.03. 176

21. Salvador R, Savarino E, Pesenti E, Spadotto L, Voltarel G, Capovilla G, Cavallin F, Nicoletti L, Valmasoni M, Ruol A, Merigliano S, Costantini M. Effects of Laparoscopic Myotomy on the esophageal motility pattern of Esophagel Achalasia as measured by High Resolution Manometry. Surg. Endoscopy 2016. doi: https://doi.org/10.1007/s00464-016-5377-9.

22. Costantini M, Salvador R, Capovilla G, Vallese L, Costantini A, Nicoletti L, Briscolini D, Valmasoni M, Merigliano S. A Thousand and One Laparoscopic Heller Myotomies for Esophageal Achalasia: a 25-Year Experience at a Single Tertiary Center. J Gastrointest Surg. 2018. doi: https://doi.org/10.1007/s11605-0183956-x.

23. Csucska M, Masuda T, Bremner RM, Mittal SK. Esophagogastric Junction Outflow Obstruction: Are We Missing Anything? J Clin Gastroenterol. 2020. doi: https://doi.org/10.1097/MCG. 0000000000001355 .

Publisher's Note Springer Nature remains neutral with regard to jurisdictional claims in published maps and institutional affiliations. 